\title{
SECURITY AWARENESS IN ROMANIA - SECURITY CULTURE AND SOCIAL RESPONSIBILITY DEVELOPMENT PILLAR
}

\author{
Paula-Diana MANTEA \\ "Mihai Viteazul" National Intelligence Academy, Bucharest, Romania \\ pauladiana.mantea@gmail.com
}

\begin{abstract}
This article brings into discussion the current state of security culture in Romania as well as the impact that the development of security education has in the training of young people who are socially responsible and aware of the importance of internalizing the basic concepts in ensuring individual and national security. The analysis continues with success factors to be pursued in public-private partnerships as a means of promoting education and security culture among young people, along with identifying recommendations for their development and improvement. Security education represents a pillar for developing a strong security culture. Therefore, increasing the security awareness among the population, especially of the young people enrolled in various educational stages, must become a priority on the strategic agendas.

This paper analyzes the steps performed so far in Romania and looks into the benefits such a strategy could bring to cybersecurity, especially by developing a framework for sustainable partnerships in the security field.
\end{abstract}

KEYWORDS: cybersecurity, ICT, security awareness, security culture

\section{Introduction}

XXI century represents, above a century of speed and technical innovation, the century of information, of a revolution of information in which data is produced in an unprecedented rhythm, globally, mainly due to the invention of the internet, which became an accessible resource almost everywhere around the globe.

In this context, worth mentioning that the number of sources from which data is obtained and transferred has multiplied. Even more important, due to its increasing accessibility, the level of awareness of the population on general topics and the risks and vulnerabilities to national and global security also have increased, by the difficulty to filtering and protecting secret data by empowered institutions, from the military and intelligence fields.
Cybersecurity becomes, therefore, a focus point, the one responsible for protecting information related to national security, to critical infrastructure, and the development of a higher security awareness level among civil population in securing data, including personal data, in the online environment represents a pillar in this process.

The approach would be interpretative, and the methods used are the historical approach, observation, and content analysis.

\section{Perspectives on the Current Security Culture Level in Romania \\ This paper represents a study in identifying the main concepts related to security culture as one main component in reducing cyber vulnerabilities in Romania. In the process, I analyzed the main studies available in 2019 in Romania regarding}


security culture, with the intent of emphasizing the impact this dimension can have in training young people in subjects related to security and social responsibility, to implement the sustainable development strategy.

In this perspective, one main factor is represented by public-private partnerships, which aim to raise security awareness for the teenagers enrolled in different educational stages. Another objective would be to identify success factors and best practices together with recommendations for their continuous improvement and enhancement.

One observation is that security education represents the main instrument for developing a strong security culture. Therefore, increasing security awareness among the population must become a priority on the strategic agendas of the security institutions.

The successful implementation of this direction implies that the management teams of both national and private actors develop actions for preventing and combating risks and vulnerabilities to cybersecurity generated by a low level of education. Secondly, this direction should focus on training a larger number of experts in the ICT sector (information communications technology), which has huge prospects for development in Romania.

Looking at the steps performed so far in Romania and the benefits such a strategy could bring to cybersecurity, especially by developing a framework for sustainable public-private partnerships in the security field, we observe that there are several organizations, which analyzed the current level of security culture based on questionnaires.

At a societal level, the security culture has several important functions. Firstly, it defines the identity of the group, a community, a society, and it provides a foundation of social solidarity around common objectives that inspire devotion, loyalty, cohesion, membership, patriotism.
Secondly, the security culture provides also the reference elements needed to design the social structure of the security and development of specific capabilities and defines patterns, behavior and attitude rules in the field of security.

It is encouraging to see that more and more research studies on the topic of education and security culture are developed at a national level, of which I mention two important studies I analyzed, Promoting Security Culture, developed by the ProSCOP organization, and The Barometer of Security Culture, elaborated by the LARICS organization in 2018. I consider them important because they are specialized in this security dimension, and they are pioneers in this field of expertise in Romania.

The first analysis, the Promoting Security Culture report includes references to the specifics of the activities that can be undertaken on this topic, such as public and strategic communication activities, influence communication and various manifestations and promotional events aimed at informing, stimulating interest, educating, and changing attitudes and behaviors of target groups (individuals or institutions). This research describes the type of activities that can be carried out by institutions with competence in security education as follows:

Public and strategic communication implies the existence of an exchange of information (messages) between public actors through channels and specific processes. Strategic communication may concern, among other things, the existence of security issues and the identification of alternative responses, the creation of a positive image of institutions with responsibilities in the field of security, increased confidence in their actions.

Influence communication involves the transmission of intentional informative content, intending to modify, transform the opinions, attitudes, and behaviors of certain categories of public concerned. The process of influence targeted in promoting security culture is an educational one and is carried out 
through awareness-raising activities like conferences, colloquia, seminars, and debates, by editing special publications, creating and disseminating media products, etc.

All these aim to achieve and consolidate the security knowledge and desired attitudes among social actors (security institutions and organizations), media institutions and the public. Examples of responsible communication structures can be found at the central administration level of:

1. The Ministry of National Defense through their Information and Public Relations Directorate;

2. The Ministry of Internal Affairs through their Information and Public Relations Directorate.

As well as at the level of the structures under the following ministries:

3. The General Staffs of the Armed Forces branches - through the Information and Public Relations Offices;

4. The Romanian Police - through the Information and Public Relations Center;

5. The Romanian Gendarmerie through the Information and Public Relations Service;

6. The Romanian General Inspectorate for Emergency Situations - through the Information and Public Relations Service (Buluc, Lungu \& Deac, 2018).

The Romanian Intelligence Service, an important guarantor of security in Romania, represents another promoter with similar activities in promoting security culture. Through a series of online articles on security awareness topics published on their intelligence portal, or shared on social networks, or in the press in general, they try to bring security concepts closer to the public and raise their awareness and interest in this field, developing a new generation of experts and influencers.

When looking into the academic offer in terms of security education in Romania, an important role in promoting security culture is one of the objectives of the military universities, through educational programs (bachelor, Master, Ph.D.) and professional development. There are six military accredited educational institutions, which are specialized in providing security education: "Alexandru Ioan Cuza" Police Academy in Bucharest, "Carol I" National Defense University in Bucharest, "Ferdinand I" Military Technical Academy in Bucharest, "Henri Coandă" Air Forces Academy in Braşov, "Mihai Viteazul" National Academy of Intelligence in Bucharest, "Mircea cel Bătrân" Naval Academy in Constanţa, and "Nicolae Bălcescu" Land Forces Academy in Sibiu.

Additionally, there are also public accredited educational institutions, which offer security studies programs, established from the need to have a common approach of all state and non-state actors involved in building a strong security culture. This approach would make possible the creation of a stable and predictable security environment, and to that extent, awareness of the fact that a broader security awareness means more freedom for the citizens, but also more security for the state. Examples of public universities, which deliver security studies, are "Alexandru Ioan Cuza" University of Iaşi, "Babeş-Bolyai" University of Cluj-Napoca, "Dimitrie Cantemir" Christian University, "Lucian Blaga" University of Sibiu, National School of Political and Administrative Studies (SNSPA), University of Bucharest, University of Oradea (Ivan, 2015).

Besides the initiatives driven within the public sector (public/governmental and academic), public-private partnerships can also be conducted with governmental and non-governmental organizations, active in the field of security and defense, such as think tanks. There are public policy research and analysis institutions, which publish, in an appropriate and accessible language, assessments, scientific research results, conclusions and recommendations on various topics of national or international interest, for the decision-makers, a framework for the design and implementation of effective public policies. 
These institutions serve the public interest, manifest themselves as independent voices and create bridges of communication and collaboration between academia and decision-makers, between national authorities and civil society. They contribute to the strengthening of an open society, which encourages the public debate forums, as well as the dissemination of information in the printed, digital or audio-video format.

Examples of such organizations include among others: Strategikon: New Strategy Center; Informational Warfare and Strategic Communication Laboratory (LARICS); "Ion Cornea" Geopolitical Association; Center for Eastern European and Asian Studies; Center for Security Studies; International Center for Security Studies, Defense and Operational Response to Crisis; Crisis Management and Conflict Prevention; Romanian Association for Societal Security; International Academic Centre for Security and Justice; Institute for Strategic Studies; "Gheorghe I. Brătianu" Geopolitical and Strategic Studies, Center for Global Studies.

Moreover, the manifestations and promotional events, as a form of unidirectional communication, can also contribute to public information and awareness on security issues and topics. Even if these types of activities are addressed to a relatively limited target audience, by mass broadcasts in the media, the number of receptors can be much higher than originally estimated.

Promotion actions are aimed at presenting new concepts, visions, strategies, strategic publications and establishing institutional or personal contacts in the field of security through participation in exhibitions, international conferences, fairs, etc.

In Romania, we can observe in recent years a strategic alignment of national institutions with international bodies to include these concepts in the fundamental national security programmatic documents. Examples of such documents are the National Defense Strategy 2015-2019: a Strong Romania within Europe and the World, the
Guide to the National Defense Strategy (2015), the National Strategy on the Digital Agenda for Romania 2014-2020, or Romania's Cybersecurity Strategy (2013). These documents highlight the desire for developing a strategic line of coordinated actions at the presidential level and, decentralizing, at ministerial, public, academic, or management level, aiming for increasing security awareness among the population.

Actions to promote security culture can be initiated by both national security institutions, and educational institutions, governmental or non-governmental organizations active in the field, under the supervision and coordination of the National Supreme Defense Council (responsible for the national defense and security actions). Such entities can belong to the Ministry of National Defense, the Ministry of Internal Affairs (MAI), the Romanian Intelligence Service (SRI), the Foreign Intelligence Service (SIE), the Special Telecommunications Service (STS), the Protection and Security Service (SPP).

These institutions designed and implemented several initiatives adapted to the current digital work and personal space. They offer digital platforms and applications to increase awareness of personal and national security topics. Some examples are:

$>D S U$ mobile app - developed by the emergency department in MAI, with free access for all smartphone users, who, in addition to the educational function through published guidelines and documentation, also represent an important alert system in case of emergency situations of local/regional/ national interest. The application is easy to use and responds to the information needs of the predominantly young population, which prefers such tools;

fiipregatit.ro platform - developed in partnership of MAI, Civic Tech Romania, the foundation for SMURD and Electrica, aiming to contributing to the education 
and training of the population for fast response and reaction time in case of emergency, both in reporting emergency cases and in being prepared and confident in alert situations reported by the authorities;

$>112$ mobile app - developed by STS, this application transmits GPS coordinates at the initiation of the emergency call and allows geo-localization, for high efficiency in the prompt response to possible emergencies;

Safe travel mobile app - developed by MAE, this tool aims to support citizens with relevant information about the country of destination where they want to travel (leisure or work travel). This includes references to the type of conditions, recommendations, and travel alerts, as well as information regarding the Romanian diplomatic mission in the country where they travel. The application allows sending notifications by which users can alert the authorities if special situations arise in the visiting country, but also the possibility to be able to alert Romania's closest mission in case of emergency. The application also includes information on procedures in case of incidents (accident, sickness, loss of acts, risks of terrorist attacks, natural disasters or conflicts in selected areas, etc.) or other similarly useful information;

TELVERDE - the dedicated permanent Anti-terrorism telephone line $(0800,800,100)$ - developed by SRI, together with their web portal (www.sri.com), provides citizens with numerous security information materials, as well as a dedicated permanent telephone line to which citizens can signal suspicious situations related to terrorist attacks.

Furthermore, even if we note that there are some informal or non-formal education initiatives, I want to stress out that security education needs an elaborated roadmap, supported by a natural learning process, developed in a formal environment. Although one step has already been undertaken by including topics of security education and security awareness in the national defense strategy, it is also necessary to align all these to the school curricula.

It is fundamental for the National Defense Strategy to be applicable in the development of the security culture by including the security education, civic culture, and social responsibility components in the national curricula. This should be adapted and implemented form the earliest segments of age, even with preschool and primary education cycles. It is important to begin with young people at these early ages, precisely because that is the moment when the system of principles, values, and norms that will shape their social life is formed (Lesenciuc, Lesenciuc \& Nagy, 2018).

In this respect, modular disciplines can be defined as part of the curriculum, in the security awareness area, addressing the importance of ownership of security and protection of personal data, but also at national and even global level. These courses can be organized both online and in the classroom; it can be modular and based on different levels of difficulty, depending on the educational cycle. These courses should include general security knowledge and cybersecurity topics in particular, but also modules on personal data protection (GDPR), safe access to a computer and mobile applications (e.g. email, navigation software, social apps, online shopping, etc.), phishing and social engineering attacks, etc.

The degree of difficulty should progressively increase and align the technical level that young people have while aiming also to bring them to an advanced set of digital skills. Such programs can become a pillar also for the training and education of a pipeline of security specialists, especially in the area of cybersecurity - a market requirement for both the public/government and the private sector.

This requirement appears listed also in the recommendations that emerge from the 
ProSCOP research, an action in the area of security culture itself, by interviewing a target group, most under 35 years old, who already have basic knowledge of security. The main conclusions of the report, extremely valuable in the analysis of promoting security culture in Romania, are:

1. Young people should represent the main target group in promoting security culture.

2. Information should be made through online media at the expense of the written press.

3. The security issue should be explained in explicit terms by building the basis for a clearer and concrete understanding of the dimensions of security by using the appropriate terminology, adapted to the age and capacity of understanding of these categories of audiences.

4. Integration of education institutions for security for both children and teenagers, and adults by organizing courses, conferences, symposia and seminars, meetings, colloquia, roundtables, debates, camps, excursions, and other recreationaleducational activities are the best way to facilitate the development of security culture.

5. The existence of a security education focusing on explaining the specific terminology, which is the basis for the development of an adequate security culture among the entire civil society - an important component of their development.

6. If the phenomenon is to be misunderstood, because of the use of overly specialized vocabulary, without semantic correspondence adapted to the level of understanding of this age category, this generation could lose interest in national security issues. This would lead to a decline in support for international security organizations, of which Romania is a member, at a regional or global level. This could also generate an increase in the perception that individual or at most national security are the dimensions that prevail and that this state of security can be achieved through individual resources or may remain a problem of the national states, which could deprive the global efforts.

7. This interpretation is also corroborated by the fact that the National Security Institutions are considered the best to promote the security culture, and the explanation could be because Romanian's trust in the defense system remains one of the highest-rated.

8. The cognitive and operational side of the security culture is considered as the most important - this is relevant since the younger generation focuses on the increase of knowledge and the depository of standard action procedures when referring to the management of security threats, risks, and vulnerabilities. They focus less on the historical facet of the security culture that is reflected in the depositary of experiences, beliefs, attitudes, traditions - these responses are indicated by most of the respondents.

9. This apparent rejection of traditions in regards to the security approach can also be explained by the fact that, in the current context, the types of threats, risks, and vulnerabilities are different. Secondly, another conclusion of the questionnaire points out that the most important concern manifested among respondents is related to the intelligence and counterintelligence dimension, which should be promoted primarily.

10. Given the increasing importance of the internet, social networks and the virtual space within society, and in addition, the role that this space plays in guaranteeing security, questionnaire respondents consider that threats launched by hostile, state or non-state entities should be tackled with priority in promoting security culture.

11. The main objective of promoting security culture is aimed at raising citizens' awareness about specific risks, threats, and vulnerabilities. The attitude that respondents experience by prioritizing this response is rather reactive than proactive, in the sense that security culture is seen as a method of 
awareness of risks, threats, and vulnerabilities and possibly to learn about management methods, not necessarily of methods to prevent them from occurring.

12. Human security should be promoted with priority. The prioritization of this response can be considered as a consequence of the risks that respondents identify as the most critical for security, namely those of a social nature: demographic decline, emigration of the active population, environmental degradation, weaknesses in the national health systems, education and social assistance, but also distortions in the labor market. All these risks directly concern individual wellbeing and social status.

13. The most outlined vulnerability to security that has been mentioned by respondents is corruption and this is a phenomenon that affects society not only in its whole but especially at an individual level (Buluc, Lungu \& Deac, 2018, pp. 47-48).

The discussion about the dimensions of the security culture continues with the model proposed by the Laboratory for Informational Warfare Analysis and Strategic Communication organization (LARICS), a model describing the parameters of the Romanian population's security culture. In this respect, LARICS conducted questionnairebased research describing the security culture in seven compact dimensions, theoretically documented and referencing the main topics of debate within the Romanian society. Each dimension matched five indicators formulated as questions. INSCOP Research applied the questionnaire on a sample of 1000 representative respondents at a national level.

The seven dimensions were formulated as seven significant polarities for the questionnaire theme:

- Trust/Mistrust;

Localism/Globalism;

Realism/Liberalism;

Optimism/Pessimism;

Security/Rights;
Involvement/Apathy;

Conspirativism/Rationalism.

The conclusions of this study reveal rather distrust in institutions than trust, rather localism than globalism, rather pessimism than optimism, rather liberalism than realism. There is a relative balance between rights centering and security centering. At least declaratively, Romanians have values associated with involvement rather than apathy in a majority percentage. Romanians have a rather conspirativist perspective on politics, media and international relations than a rationalist one (Barometrul culturii de securitate-Part. 1, 2018).

The questionnaire results also support the fact that there are no significant sociodemographic gaps in the Romanian population in terms of security culture, that there is currently no serious anti-Atlantic or anti-European inclination for the public in Romania. All three types of security culture (type $1-$ disengaged localists and isolationists - $36.6 \%$, type 2 - pragmatic and engaged rights-centered (not on security) - $29.7 \%$, type 3 - political opponents, engaged and emotional - 33.7 \%) are dominated by conspirativism and vulnerable to fake-news. The internet and television are received as conspirativist, irrational, affective and not seriously concerned about the sources (Barometrul culturii de securitate-Part. 2, 2018).

The specialists who drafted this project conclude that, by being aware of the state of the security culture, we are aware of the state of the nation's vertical and horizontal legitimacy, but also of the dominant emotions among the population and they aim to conduct this research activity in a continuous one. I salute such initiatives, which are extremely important for anybody interested in developing security awareness for specific targeted groups and prevent risks and vulnerabilities a misinformed community can cause to cybersecurity. 


\section{Conclusions}

In conclusion, we note that efforts must be made to address the problems raised by the different actors, experts in research in the security field. It should be emphasized at the central government level that through this kind of research activities the initial step has already been carried out. Following the processing and interpretation of the results, several recommendations already emerge, that provide a strong and valid starting point for designing an action plan and setting up a task force team prepared for its implementation.

Favorable results from these measures are forecast in the short, medium and long term, alongside the need to plan recurrent sessions to monitor the evolutions of this national, regional and even global security indicator. In addition to establishing a framework of standards and best practices in the security culture field, this indicator could be the ideal way to receive regular feedback from identified target groups and develop a continuous relationship with the main beneficiary of security, the citizen.

We note that there are more and more initiatives, which invest in the development of security culture in Romania, through joint efforts between private and public institutions. Analyses of the current level of security culture in Romania, the development of educational programs of security awareness and cybersecurity as preemptive measures and proactive management in ensuring security, and an increasing number of research and studies in the academia, all these complete the current scoreboard of the main initiatives that run nationally. These, alongside with all the above considerations, are arguments for which I believe that Romania is on a positive trend, with real opportunities to become much more competitive by investing in security education and, indirectly, by developing the ICT industry, and transforming into a strong European security provider through training and education of cybersecurity experts.

When analyzing the results of the existing reports and studies regarding the current state of security culture in Romania I have to mention that the situation is not satisfactory at all, because the need for information among respondents is not fulfilled thus a high level of security distrust is recorded. The statistical data and recommendations drawn from the interpretation of the results of these researches should constitute a priority on the national security agenda.

The activity undertaken through publicprivate partnership models in the security education field needs to be continuously developed and improved. Another observation is that at the security authorities level the number of initiatives and actions to ensure the required expertise for raising awareness of young people in security has begun to expand in recent years.

Reviewing the main concerns in the field as well as the conclusions generated by the analysis of the results of the research identified in the field, bring important clarifications and support the current topic, namely that security education and culture are key tools to reduce cyber vulnerabilities in Romania.

\section{REFERENCES}

Barometrul culturii de securitate - Part. 1. (2018), available at: https://arics.ro/wpcontent/uploads/2018/04/Raport-sondaj-INSCOP-barometru-LARICS-partea-1.pdf, accessed on 25 July 2019.

Barometrul culturii de securitate - Part. 2. (2018), available at: https://larics.ro/wpcontent/uploads/2018/04/Raport-sondaj-INSCOP-barometru-LARICS-partea-2.pdf, accessed on 25 July 2019. 
Buluc, R., Lungu, C., \& Deac, I. (2018). Perceptions on Security Culture. Redefining Community in Intercultural Context, Vol. 7, 149-157, Bucharest: "Henri Coandă" Air Force Academy Publishing House.

Buluc, R., Lungu, C., \& Deac, I., (2018). Promovarea culturii de securitate. Raport. București: Asociația ProSCOP.

Ivan, A. L. (2015). Studii de Securitate în universitățile românești, available at: https://intelligence.sri.ro/studii-de-securitate-universitatile-romanesti, accessed on 05 August 2019.

Lesenciuc, A., Lesenciuc, S., \& Nagy, D. (2018). The Symbolic Power: National Security Culture Reflected in Primary and Pre-Primary Education. Redefining Community in Intercultural Context, Vol. 7, pp. 93-102, Bucharest: "Henri Coandă" Air Force Academy Publishing House.

National platform for emergency preparedness. (2019), available at: https://fiipregatit.ro/, accessed on 25 July 2019.

Romania the Presidential Administration. (2015). Guide to the National Defense Strategy, available at: http://old.presidency.ro/static/Ghid\%20SNApT 2015-2019 AP.pdf, accessed on 07 August 2019.

Romania the Presidential Administration. (2015). National Defense Strategy 2015-2019: a Strong Romania within Europe and the World. Bucharest, available at: https://www.presidency.ro/files/userfiles/National_Defense_Strategy_2015__2019.pdf, accessed on 07 August 2019.

The Government of Romania. (2013). Romania's Cybersecurity Strategy, available at: https://www.enisa.europa.eu/topics/national-cyber-security-strategies/ncssmap/StrategiaDeSecuritateCiberneticaARomaniei.pdf, accessed on 10 August 2019.

The Ministry for the Information Society. (2014). National Strategy on the Digital Agenda for Romania 2020, available at: https://www.juridice.ro/wp-content/uploads/ 2014/12/Strategia-Nationala-AD.pdf, accessed on 10 August 2019. 